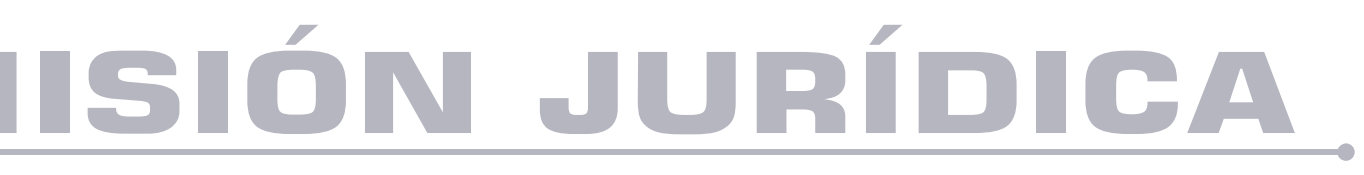

\title{
Aproximaciones generales para abordar el Sistema Penal Acusatorio
}

General approximations for tackling the Accusatory

Criminal System

Autores: Luis Eduardo Martínez Gutiérrez, Ingrid Lorena Parrado Leal

DOI: https://doi.org/10.25058/1794600X.1922

\footnotetext{
SP MISIÓN JURÍDICA A 


\title{
APROXIMACIONES GENERALES PARA ABORDAR EL SISTEMA PENAL ACUSATORIO*
}

\author{
General approximations for tackling the Accusatory Criminal \\ System
}

Abordagens gerais para lidar com o sistema penal acusatório

Luis Eduardo Martínez Gutiérrez ${ }^{\mathrm{a}}$

lemartinez@unicolmayor.edu.co

Ingrid Lorena Parrado Leal ${ }^{\text {b }}$

abingridparrado@gmail.com

Fecha de recepción: 10 de junio de 2020

Fecha de revisión: 6 de julio de 2020

Fecha de aceptación: 22 de septiembre de 2020

DOI: https://doi.org/10.25058/1794600X.1922

Para citar este artículo:

Martínez Gutiérrez, L. E. y Parrado Leal, L. (2021). Aproximaciones generales

para abordar el Sistema Penal Acusatorio. Revista Misión Jurídica, 14, (20).

para abor

\section{RESUMEN}

Este artículo resume las características básicas del actual sistema penal que rige el ordenamiento jurídico. Resaltando sus etapas, sus principios rectores y las actuaciones principales, para que quien se aproxime por primera vez o con intención de entender el sistema, tenga un punto de partida concreto, sencillo y accesible para todo público, sin olvidar el rigor técnico propio del derecho. En este sentido, el objetivo principal es explicar la dinámica del sistema procesal de la Ley 906 de 2004; y como objetivo secundario, hacer algunas recomendaciones para su mejoramiento.

\footnotetext{
*Artículo de reflexión.
}

a. Ex Decano de la facultad de Derecho de la Universidad INCCA. Ex director de la especialización en Derechos Humanos de la Universidad INCCA. Docente de la Universidad Colegio Mayor de Cundinamarca. Docente de la Universidad Libre de Colombia. Ex director de la revista jurídica Derecho y Sociedad- Unincca.

b. Ex docente Derecho Universidad INCCA. Ex docente Ad Honorem Universidad Sergio Arboleda. 


\section{PALABRAS CLAVES}

Sistema penal acusatorio; normas rectoras; principios rectores; Ley 906 de 2004; imputación; acusación; audiencia preparatoria; juicio oral; constitucionalización proceso penal.

\section{ABSTRACT}

This article summarizes the basic characteristics of the current penal system that governs our legal system. Highlighting its key stages, guiding principles and main actions so that anyone who explores the topic for the first time or with the intention of understanding the system, has a concrete, simple and accessible starting point suitable for all the public, without forgetting the proper technical rigor of law. That is why the main objective is to explain the dynamics of the procedural system of Law 906 of 2004 , and as a secondary objective, to make some recommendations for its improvement.

\section{KEY WORDS}

Accusatory criminal system; governing rules; guiding principles; law 906 of 2004; imputation; accusation; preparatory hearing; oral trial; constitutionalization of the criminal process.

\section{RESUMO}

Este artigo sintetiza as características básicas do atual sistema penal que rege o ordenamento jurídico. Destacando as suas etapas, os seus princípios norteadores e as principais ações, para que quem se aproxima pela primeira vez ou com o intuito de compreender o sistema, tenha um ponto de partida concreto, simples e acessível a todos os públicos, sem esquecer o rigor técnico da lei . Nesse sentido, o objetivo principal é explicar a dinâmica do sistema processual da Lei 906 de 2004; e como objetivo secundário, fazer algumas recomendações para a sua melhoria.

\section{PALAVRAS-CHAVE}

Sistema criminal acusatório; normas que regem; princípios orientadores; Lei 906 de 2004; imputação; acusação; audiência preparatória; ensaio oral; constitucionalização do processo penal.

\section{INTRODUCCIÓN}

Apelando a la experiencia que se tiene como catedráticos y litigantes sobre el sistema penal acusatorio, sumado a los múltiples estudios realizados sobre este, $y$, teniendo en cuenta la cantidad de jurisprudencia al respecto, se presenta este artículo, dirigido principalmente a estudiantes $y$, en general, a quienes quieran entender de manera sencilla la dinámica del sistema.

Inicialmente, una aclaración: no se pretende dar una clase completa de la Ley 906 de 2004 (Código de Procedimiento Penal), o cómo funciona el mal llamado Sistema Penal Acusatorio; este breve artículo es solo una reflexión sobre los puntos principales para entender el funcionamiento del sistema en la práctica $\mathrm{y}$, algunas proposiciones con miras a la mejora de este $y$, se reitera, se encuentra dirigido a estudiantes $y$, en general, a quienes quieren entender de manera sencilla dicho modelo.

Así que con el respeto que merecen varios "Tratadistas y Doctrinantes", este escrito apela a la brevedad y a la sencillez de los conceptos, aborda su entendimiento desde la práctica y, sin recurrir a un lenguaje confuso, retorico, rebuscado o selecto para ilustres.

Para estos efectos, se hará referencia histórica y se pasará al abordaje de los principios procesales o denominados normas rectoras, se estudiarán los intervinientes, la estructura procesal relevante y, finalmente, se hará un balance y se destacarán algunas ideas para mejorar la legislación penal.

\section{DESARROLLO DEL TRABAJO}

Para empezar, la legislación procesal penal, -solo para referir los antecedentes próximos -, ha tenido los siguientes Códigos de Procedimiento Penal: el Decreto 050 de enero 13 de 1987 (Presidencia de la República), el cual rigió antes de entrar en vigor la Constitución de 1991 y, antes de la creación de la Fiscalía General de la Nación, evidentemente era de tendencia inquisitiva, ya que quien investigaba y juzgaba era la rama jurisdiccional.

Posteriormente, el decreto 2700 de 30 de noviembre de 1991 (Presidencia de la República) se emitió en vigencia de la Constitución de 1991, e introdujo a la Fiscalía General de la Nación como el nuevo acusador, dejando atrás al juez 
acusador. Entró en vigor el 1 de julio de 1992. Este proceso penal tendió a ser mixto, algo se mantuvo del sistema inquisitivo, pero se instó a la acusación como un acto aparte de quien investigaba adoptando así características del modelo acusatorio.

Entrando a los códigos vigentes, tenemos la Ley 600 de 24 de julio de 2000 (Congreso de Colombia) que entró en vigor el 24 de julio de 2001 que derogó la anterior legislación, hoy se mantiene excepcionalmente para aforados y algunos casos que no han sido resueltos, pero que por el principio de legalidad están a la espera de prescribir o de obtener alguna respuesta de la justicia.

Igualmente, la Ley 906 de agosto 31 de 2004 (Congreso de la República), introdujo el, mal llamado, sistema penal acusatorio, la cual entró en vigor por regiones, en diferentes fechas y parcialmente, debido, entre otras cosas a la falta de condiciones técnicas y de capacitación de los diferentes actores del sistema. Aunque, hoy en día tiene plena vigencia en todo el territorio nacional. Ha sido modificada en varias ocasiones: por la Ley 1826 de 2017, por la Ley 1786 de 2017, por la Ley 1760 de 2015, Por la Ley 1542 de 2012, por la Ley 1474 de 2011, por la Ley 1453 de 2011, por la Ley 1395 de 2010 y por la Ley 1121 de 2006.

Finalmente, el acto legislativo 6 de 2011, introdujo el nuevo parágrafo $2^{\circ}$ al artículo 250 constitucional que contiene la excepción al principio de oficiosidad, obligatoriedad, continuidad e irrenunciabilidad de la acción penal, radicados en cabeza de la Fiscalía General de la Nación, con dicho marco constitucional se expide la Ley 1826 de 12 de enero de 2017 (Congreso de la República), con el propósito de dar simplicidad procesal y obtener una justicia pronta y eficaz; estatuto que entró a regir seis meses posteriores a su promulgación, y creó el procedimiento penal abreviado, para ciertos delitos y con determinadas condiciones. Adicionalmente, reguló la institución de conversión de la acción penal de pública a privada en determinados casos.

Con este panorama, queda por sentado que coexisten por lo menos tres procedimientos penales ordinarios, sin mencionar los procedimientos especiales como los de fuerzas armadas que no serán objeto de abordaje.

\section{DE LOS PRINCIPIOS RECTORES Y GARANTÍAS PROCESALES}

Hay una discusión que no será abordada y es: si los principios y normas son iguales y si lo regulado en los artículos 1 a 27 del Código de Procedimiento Penal, responden a una u a otra categoría especifica. Valga decir que el principio y la norma son diferentes y que el título preliminar incluye tanto normas como principios que en todo caso son de obligatorio cumplimiento por parte de los operadores judiciales y es lo que debe importar para los efectos de este escrito.

Ahora bien, la introducción de esos artículos corresponde al proceso de constitucionalización del derecho procesal penal, es decir que las normas rectoras, solo son el reflejo del catálogo de derechos fundamentales de la Constitución Política y del bloque de constitucionalidad. Esto se reflejó en la Ley 600 de 2000 y evidentemente en la Ley 906 de 2004, en la cual se incluyeron expresamente principios y normas rectoras dirigidas a los aplicadores del derecho, con miras a que no se desconociera la propia Constitución que en ultimas busca beneficiar al procesado y en general brindar una garantía de seguridad a todos los ciudadanos. Claro, hoy en día habría que agregar que dichas normas y garantías también cobijan a la víctima y a los demás intervinientes en el proceso.

Bernal y Montealegre (2013) establecen como finalidad principal de esta realidad el condicionamiento de la estructura del procedimiento penal a la materialización de los derechos y en definitiva lograr una aplicación justa de las normas penales (Derecho Procesal Penal).

Estos principios y normas rectoras están consagrados a partir del artículo primero del título preliminar, empieza por la dignidad humana; artículo segundo sobre la Libertad; artículo tercero regula la Prelación de los tratados internacionales en concordancia con lo establecido en el artículo 93 de la Constitución Política; artículo cuarto Igualdad; artículo quinto Imparcialidad; artículo sexto Legalidad; artículo séptimo Presunción de inocencia e in dubio pro reo; artículo octavo Defensa; artículo noveno Oralidad; artículo decimo Actuación procesal con respeto de derechos fundamentales. 
Hay que enfatizar en que el bloque de constitucionalidad por disposición expresa del artículo tercero del C.P.P., es de obligatoria aplicación en las diferentes decisiones de los operadores jurídicos. Y que esta figura busca incluir en la legislación los parámetros normativos del derecho internacional de los derechos humanos (Escuela Judicial Rodrigo Lara Bonilla, 2005).

Dando continuidad, Artículo 11 Derechos de las víctimas; artículo 12 Lealtad; artículo decimo 13 Gratuidad; artículo 14 Intimidad; artículo 15 Contradicción; artículo 16; artículo 17 Concentración; artículo 18 Publicidad; artículo 19 Juez natural; artículo 20 Doble instancia; artículo 21 Cosa Juzgada; artículo 22 Restablecimiento del derecho; artículo 23 Cláusula de exclusión; artículo 24 Ámbito de la jurisdicción penal; artículo 25 Integración; artículo 26 Prevalencia; artículo 27 Moduladores de la actividad procesal.

Es de resaltar que se fusionaron garantías en un solo artículo, tal es el ejemplo del artículo octavo que consagró el derecho a la defensa en el que se condensaron la confrontación, contradicción, el debido proceso, entre otros. Igualmente se introdujeron normas que no estaban en la legislación anterior de las cuales se resaltará la establecida en el artículo 27, de la que emana una orden directa a los jueces penales para que motiven y argumenten sus decisiones conforme los criterios de necesidad, ponderación, legalidad y corrección en el comportamiento.

Estas garantías constitucionales y judiciales pueden clasificarse, así: 1. Según su contenido: unas reglas referidas propiamente al procedimiento (artículos 6, 7. 8, 9, 10, entre otras), otras relacionadas con los funcionarios que dirigen el proceso $(9,10,24,25,26$ y 27 , entre otras) y otras tendientes a regular el tema de la prueba (artículo 23).

La anterior no es la única clasificación posible, de hecho, la doctrina española clasifica los principios en los del proceso y los del procedimiento (Calaza, et al, 2019). Los del proceso: acusatorio, es decir, diferencia entre quien acusa y quien juzga, igualdad, contradicción, oficiosidad, libre valoración de la prueba, proporcionalidad y legalidad/oportunidad y del procedimiento: oralidad, inmediación, concentración, celeridad, entre otros (Arnaiz, López y Martínez, 2013).

\section{DE LOS ACTORES PRINCIPALES DEL SISTEMA}

Oportuno es abordar los principales actores del sistema con los cuales se irán desarrollando las normas rectoras en un aspecto material, por lo tanto se apela no a una definición de estás, sino a una dimensión práctica.

Los actores del sistema son: el Indiciado, imputado, acusado y condenado (defensa material); el Abogado defensor (defensa técnica); el Investigador (función de policía judicial); el Fiscal (acusador y director de la investigación); el Juez de control de garantías; el Juez de conocimiento; la Victima y el Ministerio Público.

En lo que tiene que ver con la defensa material es importante resaltar que esta debe entenderse en concordancia con el artículo 29 de la Constitución Política (Asamblea Nacional Constituyente, 1991), artículo octavo del Pacto de San José de Costa Rica (Organización de Estados Americanos, 1969). Adicionalmente, varias sentencias de constitucionalidad que han tratado sobre este derecho, entre las cuales se pueden mencionar, como relevantes: C - 089 de 2011, C 127 de 2011, C - 838 de 2013, C - 496 de 2015, y recientemente la $\mathrm{C}-559$ de 2019.

$\mathrm{Al}$ respecto, solo se mencionará una situación crítica y es desde cuando se tiene derecho a ejercer la defensa material y técnica dentro del proceso penal y, si existe una obligación en cabeza de la Fiscalía de comunicar esta circunstancia a quien se está indagando. Sobre el particular la sentencia de constitucionalidad C - 559 de 2019, parece dar una luz a estos interrogantes.

En efecto, en dicha providencia la Corte tuvo la oportunidad de analizar la constitucionalidad de la Ley 1908 de 2018, que introdujo algunos artículos y modificó otros tantos al Código de Procedimiento Penal, con el objeto de persecución de grupos armados organizados y en general para darle trato diferenciado al crimen organizado.

Para resumir, la Corte ratificó que el derecho de defensa es intemporal y que desde que se tenga conocimiento de la indagación e investigación en contra, se tienen todas las garantías que contempla el artículo octavo del Código de Procedimiento Penal, "el implicado debe tener 
acceso a todas las herramientas que le permitan ejercer su derecho a la contradicción, desde el momento en el que conoce de una actuación penal en su contra, es decir, desde la etapa de indagación" (Sentencia de Constitucionalidad, 2019 , p. 36). Y la reserva absoluta introducida por la ley debe ser interpretada por motivos de protección de seguridad de la víctima, testigos, entre otros.

Lo anterior, es una ratificación y condensación de líneas ya trazadas por la Corte Constitucional en varias sentencias como: C - 799 de 2005, C-873 de 2003, C-591 de 2005, C-1194 de 2005 y C-025 de 2009, en las cuales ya se afirmaba que en el ordenamiento constitucional existe una intemporalidad del derecho de defensa.

En lo que tiene que ver con la víctima, catalogada por la Corte Constitucional como un interviniente especial, se ha dicho que en la medida en que tenga un interés jurídico para actuar, y en términos generales pueda acreditar un daño real, cierto y especifico, puede participar en todas las etapas del proceso penal, inclusive, en la etapa de juicio, aunque por intermedio de la Fiscalía General de la Nación (Sentencias de Constitucionalidad, 2002 y 2007).

En Colombia, al igual que en países como en Argentina, la victima ha ido adquiriendo cada vez más prerrogativas y ha sido cada vez nutrida (Báez, et al, 2013). Es así como en un principio se le notificaba sobre el inicio de la investigación, estando limitada su capacidad, hoy en día, inclusive puede hacer solicitudes probatorias por intermedio de la Fiscalía.

Finalmente, se resalta lo siguiente: hay un deber de comunicación que recae en la Fiscalía General de la Nación, así lo dice la Corte:

la restricción contemplada en la norma operará frente a documentos o datos personales que comprometan la vida o la integridad física de testigos, víctimas o funcionarios...pero no frente al hecho mismo del inicio de la indagación, de lo cual deberá ser informado el indagado de conformidad con la jurisprudencia antes citada (Sentencia de Constitucionalidad, 2019, p. 42).

Ahora bien, la figura del Ministerio Público -MP- dentro del proceso penal como un interviniente especial es extraña e inoportuna porque inclina la balanza, usualmente hacia el lado de la Fiscalía, dejando al investigado en una situación de desigualdad y de incertidumbre ante dos posibles acusaciones. Igualmente, deslegitima la propia función acusadora de la Fiscalía y lo mismo de la función judicial correspondiente a los jueces de control de garantías y de conocimiento.

Los demás actores del proceso, aunque merecen una explicación de su rol, basta con decir que la Fiscalía es la encargada de hacer la indagación, la investigación y la acusación de los hechos que revistan las características de delito y para esto se vale de la Policía Judicial que es, más que una autoridad, es una función que está en cabeza de miembros de la Policía Nacional, de autoridades administrativas, del Cuerpo Técnico de Investigaciones -CTI-, entre otras.

\section{ESTRUCTURA DEL SISTEMA ACUSATORIO}

El sistema cuenta con tres etapas: indagación, investigación y juicio. Estas se activan por la fiscalía titular de la acción, Art. 250 constitucional; así las cosas, la indagación tiene lugar con la noticia criminal, la investigación con la formulación de imputación y el juicio con la radicación del escrito de acusación verbalizado en audiencia.

La Indagación tiene por objeto establecer si unos hechos determinados reúnen las características para ser considerados como delito y quienes son los presuntos autores o participes. Esta actividad en principio es reservada, no obstante, habrá que tenerse en cuenta la jurisprudencia al respecto, en la cual la reserva no opera de forma general, sino que se limita a ciertos eventos y para ciertos actores y que, en todo caso, una vez identificada e individualizada la persona presuntamente autora deberá comunicársele de dicha averiguación.

Esta etapa va desde la noticia criminal, pasando por el programa metodológico en el que se plantee la hipótesis delictiva, hasta cuando aparezcan elementos materiales probatorios o información legalmente obtenida, de la cual se pueda inferir razonablemente que el indiciado pudo ser el autor o participe del delito investigado, y formularle la imputación, a no ser que opere la prescripción de la acción que es su límite. También puede suceder que el fiscal al evaluar el caso con base en los elementos materiales probatorios considere 
que no hay motivos o circunstancias para estar en presencia de un delito, podrá archivar las diligencias conforme el artículo 79 del CPP.

Vale la pena aclarar que según el artículo 175 del CPP (Congreso de la República, 2004), la Fiscalía tiene un plazo máximo de dos, tres y cinco años dependiendo del concurso de conductas o de imputados, contados desde la recepción de la noticia criminal para formular imputación o archivar la investigación. No obstante, la norma no establece ninguna consecuencia si no se lleva a cabo en ese lapso. Por eso se puede afirmar que el único límite será el término de prescripción de la acción.

Ahora bien, la noticia criminal puede provenir de fuentes formales como la denuncia, querella, petición especial, por informe o de oficio, como de fuentes no formales de la cual hacen parte las llamadas telefónicas, las noticias difundidas por medios de comunicación, anónimos, informantes, y correo electrónico. Salvo los delitos que requieren querella de parte que solo tiene hasta seis meses para presentarla, la noticia criminal puede presentarse en cualquier momento, siempre y cuando no esté prescrita la acción penal.

Una vez recepcionada la noticia criminal los actos de investigación competen a la Fiscalía General de la Nación por intermedio de su delegado, quien dirija la investigación, con ayuda de la policía judicial, quien puede realizar actos propios y ejecuta las ordenes de la fiscalía tendientes a recoger $\mathrm{y}$ embalar elementos materiales probatorios. Salvo los actos urgentes en los cuales no se requiere ninguna orden del Fiscal, pero que usualmente una vez designado todas las ordenes deben provenir de este.

Los actos urgentes a los que se hace mención se encuentran en el artículo 205 del CPP, tales como inspección en el lugar del hecho, inspección de cadáver, entrevistas e interrogatorios los cuales deben registrarse por escrito, grabación magnetofónica o fonóptica y se someterá a cadena de custodia. Esto quiere decir que se debe identificar, recoger, embalar técnicamente los elementos materiales probatorios y evidencia física. Sobre esos actos urgentes y sus resultados la policía judicial deberá presentar, dentro de las treinta y seis (36) horas siguientes, un informe ejecutivo al fiscal competente para que determine si se sigue una indagación, si no hay necesidad de ella y por tanto imputa, o en caso de capturas en flagrancia se proceda a su legalización, esto dependerá de la elaboración del plan metodológico que para el efecto elabore el Fiscal con la ayuda del Policía judicial.

Dentro de ese programa metodológico se contemplan actividades investigativas que pueden ser de dos tipos: las que requieren una solicitud por parte de la Fiscalía para su realización a un Juez de Control de Garantías, es decir solicitud previa para su realización; y las que pueden llevarse a cabo por orden del Fiscal del caso y posteriormente pueden ser legalizadas ante el Juez.

Dentro del primer grupo, el artículo $246 \mathrm{del}$ CPP (Congreso de la República, 2004) establece por regla que general que las actuaciones diferentes a las del segundo grupo, solo se podrán realizar con autorización previa del Juez de Control de Garantías; así las cosas, en los artículos siguientes da una serie de actividades investigativas, pero, que en todo caso debe seguirse la regla general ya dicha.

Dentro del segundo grupo, las que no requieren autorización judicial previa (art. 213 CPP), se encuentran la inspección al lugar del hecho, la inspección al cadáver, la exhumación, registros y allanamientos especiales (art. 219 CPP), retención de correspondencia e interceptaciones, la recuperación de información dejada al navegar por internet, vigilancia $y$ seguimiento de personas, vigilancia de cosas, actuación de agentes encubiertos inclusive en modalidad virtual (art. 242B CPP), entrega vigilada, búsqueda selectiva en base de datos, exámenes de ADN que involucren al indiciado o al imputado, siempre que este haya dado su consentimiento. Estas actuaciones, con excepción de las primeras, deben estar precedidas de una orden del Fiscal en la cual establezca los motivos fundados para limitar los derechos fundamentales de los sujetos pasivos de dichas ordenes, y en todo caso se deberá posteriormente presentar al Juez de Control de Garantías para su legalización.

Así las cosas, si el Fiscal encuentra que, de los elementos materiales probatorios, evidencia física o de la información obtenida, se puede inferir razonablemente que el imputado es autor o participe del delito que se investiga, hará la 
solicitud al centro de servicios judiciales del lugar de comisión del hecho para formular la imputación ante el Juez de Control de Garantías. Este Juez no puede ejercer un control material de la misma y solo se limita a verificar que se cumplan con los requisitos del artículo 287 del CPP (Congreso de la República, 2004).

Entonces, una vez formulada la imputación inicia la fase de investigación propiamente dicha. La Imputación como acto de parte es el acto a través del cual la Fiscalía General de la Nación comunica a una persona los hechos jurídicamente relevantes, es decir las circunstancias de tiempo modo y lugar en las cuales presuntamente se violó una norma penal $\mathrm{y}$, por tanto, el Juez le notifica su calidad de imputado. A este respecto es importante traer a colación lo dicho por la Corte Suprema de Justicia en la Sentencia de Casación, de 5 de junio de 2019, Radicado 51.007, Magistrada Ponente: Patricia Salazar Cuellar, en la cual llamó la atención a la Fiscalía General de la Nación para que la imputación girara entorno a los hechos jurídicamente relevantes, entendidos estos como los que guardan relación con las normas penales violadas o transgredidas.

Con la imputación se interrumpe la prescripción de la acción penal, en esa audiencia preliminar se puede solicitar la imposición de mediad de aseguramiento, siempre que reúna los requisitos del Art. 308 del CPP (Congreso de la República, 2004). Igualmente, puede pedir medidas cautelares sobre bienes, personas jurídicas, entre otras. Debe admitirse que pocas veces se hace uso de estas medidas cautelares dejando en grave perjuicio a la víctima para garantizar sus derechos de indemnización integral.

Si en la imputación de cargos efectuada, el delito No comporta detención preventiva, el aprehendido o capturado deberá ser liberado de manera inmediata. Es importante advertir que una vez se adquiere la calidad de imputado le asiste el compromiso de presentarse al proceso cuantas veces sea necesario, de no hacerlo se podrá declarar en contumacia.

De igual manera, el imputado puede acogerse a las formas de terminación anticipada del proceso, ya sea mediante las formas consensuadas como los preacuerdos o los principios de oportunidad, los cuales están sometidos a un control formal por parte del Juez de Control de garantías, si es un preacuerdo o un Juez de Control de conocimiento; o no consensuada como el allanamiento puro y simple.

Contrario sensu, si no hay lugar a la terminación anticipada, lo que procede es la radicación del escrito de acusación por parte del Fiscal, una vez realizado este acto, se asignará un Juez de Conocimiento, cuya función es llevar a cabo el juicio sin haber tenido ningún contacto anterior con el proceso. Por tanto, se excluyen jueces que hayan intervenido en la fase de investigación o que hayan resuelto recursos respecto de alguna de las audiencias preliminares.

Ahora bien, una vez formulada la imputación, la Fiscalía cuenta con un término de 90 días para radicar el escrito de acusación o solicitar la preclusión, a no ser que sean tres o más los imputados o haya concurso de delitos, caso en el cual el plazo se amplía a 120 días (art. 175 CPP).

El fiscal durante esta fase puede entre otras decisiones, dar aplicación al principio de oportunidad, solo si hay aprobación de este mediante único acto del Juez de Control de Garantías, el cual esta reglado en 18 causales, aunque una de ellas, la causal 17, fue declarada inconstitucional, mediante la sentencia C- 936 de 2010. Esta prerrogativa de la Fiscalía implica que al ser titular exclusivo de la acción penal puede solicitar suspender, interrumpir o renunciar a la persecución penal.

De no existir mérito para acusar, el Fiscal, puede solicitar la preclusión de la investigación, lo propio el Ministerio público o la defensa en la etapa del juicio por las causales 1 y 3 del artículo 332 del CPP., como una forma de terminación del proceso penal que hace tránsito a cosa juzgada y debe ser adoptada por el Juez de Conocimiento, siempre que se reúnan las causales de que trata el Art. 332 del CPP.

Retomando, una vez radicado el escrito de acusación inicia la etapa de Juicio. Esta etapa la integran cuatro importantes audiencias: la de formulación de acusación, la preparatoria, de juicio oral y, de individualización de pena y sentencia. Posteriormente y ante la sentencia de carácter condenatorio puede darse el trámite del incidente de reparación. 
La etapa de juicio es la vértebra (la audiencia preparatoria) del nuevo sistema. Está a cargo del juez de Conocimiento y tal como se refirió, se inicia con la presentación del escrito de acusación que debe reunir la plenitud de los requisitos del Art. 337 del CPP (Congreso de la República, 2004). El Juez tampoco ejerce un control material de esa acusación tal como la Corte Suprema de Justicia lo ha venido ratificando (Auto de sustanciación, 209).

El escrito de acusación es un documento mediante el cual el Fiscal, informa al juez de conocimiento, a la defensa, al Ministerio Público y a la victima de: los hechos jurídicamente relevantes que constituyen una conducta punible $\mathrm{y}$, mediante el anexo pone de presente los elementos materiales probatorios y evidencia física que llevará a juicio para buscar la condena del imputado.

\section{AUDIENCIA DE FORMULACIÓN DE ACUSACIÓN}

La acusación es un acto complejo que se integra de dos elementos, uno netamente de parte, que concreta con la radicación del escrito de acusación y que debe reunir los requisitos del artículo 337 del CPP (Congreso de la República, 2004). En general, se requiere individualización de quien ya fue imputado, una relación de los hechos jurídicamente relevantes, lugares de citación de las partes y la enunciación de las pruebas que pretenden hacer valer en el juicio.

Dice el artículo 338 que tres días después de recibido el escrito se citará a la audiencia de acusación. Esta es la primera audiencia de la etapa de juicio y su trámite se encuentra regulado en el artículo 339 del CPP (Congreso de la República, 2004). Allí el Juez concederá la palabra a los sujetos intervinientes para que manifiesten si tienen alguna causal de impedimento 0 recusación, nulidades y observaciones al escrito de acusación. Acto seguido, el Fiscal procederá a formular la acusación, constituyendo esto la segunda parte del acto complejo de la acusación como acto de parte que. Tal como se advirtió, no tiene control material por parte del Juez.

En esta audiencia también se reconoce la calidad de victima dentro del proceso, así lo establecen los artículos 132 y 340 del CPP (Congreso de la República, 2004). La victima dentro del proceso penal ha adquirido cada vez más relevancia. Inclusive, puede hacer descubrimiento y solicitudes probatorias por intermedio de la Fiscalía. Esto sin desconocer las múltiples sentencias de constitucionalidad que han ratificado que en todos los delitos la victima puede participar desde la etapa de indagación e investigación (Sentencia C-209/07).

Puede que el descubrimiento probatorio material, es decir el acceso a los elementos de prueba por parte de la defensa se haga fuera de audiencia de acusación, caso en el cual, por solicitud de la defensa, o porque los hechos del caso así lo determinen el descubrimiento puede terminarse por fuera de la audiencia de acusación cuya verificación se hará en la audiencia preparatoria.

Al lado de ello, se debe dejar claro que puede haber lugar a aclarar, adicionar o corregir el escrito de acusación, sea por iniciativa de la Fiscalía o por petición de la Defensa, Victima o el Ministerio Público (Saray, 2017). Igualmente, que caben las observaciones hechas con prelación sobre los hechos jurídicamente relevantes y la necesidad de que estos sean evidenciables en los escritos de acusación.

De hecho, la Corte Suprema de Justicia ha puesto varias veces en evidencia la necesidad de diferenciar los hechos jurídicamente relevantes de los medios de prueba, de los indicios y de los hechos indicadores. En algunos casos, incluso se ha llegado a la absolución por esa falta de concreción y prueba de estos.

Llevada a cabo en debida forma la acusación se procede a programar audiencia preparatoria del Juicio Oral. Puede ocurrir que se presente alguna solicitud de nulidad, impedimento o recusación, caso en el cual se debe acudir a lo establecido en el artículo 341 del CPP (Congreso de la República, 2003).

\section{AUDIENCIA PREPARATORIA}

Es la audiencia más importante antes del juicio, allí las partes harán las solicitudes probatorias tendientes a lograr la declaratoria de culpabilidad o la absolución del acusado conforme su teoría del caso. Hay una carga argumentativa de las partes respecto de elementos materiales probatorios que se convertirán en pruebas en el juicio, por tal razón se debe explicar con claridad y brevedad al juez de su pertinencia, conducencia y admisibilidad. 
Desde el artículo 355 del C.P.P. se regula lo concerniente a la instalación y establece que es indispensable la presencia del Juez, el Fiscal y el Defensor. Es decir, puede llevarse a cabo sin la presencia de la víctima y del Ministerio Público.

Instalada la audiencia, cuya finalidad es planear, delimitar y determinar la actividad probatoria que se desarrollará en la audiencia de juicio oral. Cada parte optará por demostrar su teoría del caso, existiendo para la defensa en esta audiencia la obligación de descubrir lo elementos materiales probatorios o evidencias físicas que pretenda hacer valer en el juicio como pruebas y la manifestación que deban hacer las partes si se tiene interés en hacer estipulaciones probatorias.

La importancia de esta audiencia, está en las solicitudes probatorias, lo cual implica que las partes puedan solicitar las pruebas que requieran con el fin de sustentar su teoría del caso, para lo cual el juez de conocimiento tendrá en cuenta las reglas de pertinencia y admisibilidad. Excepcionalmente el ministerio público podrá pedir la práctica de pruebas que tuviere conocimiento, pero que no fue pedida por las partes. Se debe advertir que este nuevo estatuto procesal prohíbe el decreto de pruebas de oficio o por parte del juez en el artículo 361 del CPP (Congreso de la República, 2004).

No obstante lo anterior, la Corte Constitucional en sentencia C - 396 de 2007, dijo que esta prohibición no era absoluta y que los Jueces de Garantías podrían decretar pruebas de oficio en los casos en que era indispensable garantizar la eficacia de los derechos que eran objeto de control judicial (Sentencia de Constitucionalidad, 2007). Por su parte la Corte Suprema de Justica mediante auto de sustanciación AP2356-2018, radicación No. 50.213 de 30 de mayo de 2018, expresó que en efecto la prohibición no es absoluta y que el juez puede en otras etapas procesales diferentes al juicio ordenar pruebas de oficio (Auto de Sustanciación, 2018).

Es evidente que en la etapa del juicio hay prohibición absoluta de practica oficiosa de pruebas, esto en pro de garantizar la neutralidad del juez y de respetar la presunción de inocencia del acusado. La excepción a esta regla estaría dada para los jueces de Control de Garantías siempre que se requiera proteger el derecho fundamental objeto de debate.
Respecto de la solicitud probatoria del Ministerio Público, valga decir que es de carácter excepcional y que tal como lo refirió en auto interlocutorio de 8 de octubre de 2015, de la Corte Suprema de Justicia:

los roles de quienes intervienen en audiencia preparatoria estarán plenamente definidos; así, la Fiscalía peticionará la práctica de las pruebas que estén dirigidas a sustentar la acusación y la necesidad de la pena; las víctimas las que conduzcan a demostrar la responsabilidad penal del acusado $y$, excepcionalmente, el Ministerio Publico, solicitará la práctica de aquellas que no habiendo sido requeridas por las partes, pudieran tener esencial influencia en el resultado del juicio (Auto Sustanciación, 2015).

Hechas las solicitudes probatorias, el Juez hará una depuración de estas, así las cosas, aprobará o rechazará algunas de ellas y establecerá el orden en el que serán presentadas en el juicio oral, atendiendo a la teoría del caso de la Fiscalía y de la defensa respectivamente. Constatado lo anterior se fijará fecha para llevar a cabo la audiencia de juicio oral.

\section{AUDIENCIA DE JUICIO ORAL}

Es el acto procesal más importante del proceso penal acusatorio. Se realiza ante el juez de conocimiento que funge como tercero neutral e imparcial. Es una audiencia que por regla general es pública, aunque excepcionalmente puede ser de carácter reservado cuando se atienda a un interés superior tal es el caso de las víctimas de delitos sexuales. En esta audiencia se ponen en observancia los principios procesales de oralidad, inmediación, concentración y contradicción de las pruebas, garantizando la igualdad de las partes.

Esta audiencia tiene tres fases importantes. la primera, corresponde a los alegatos de apertura; la segunda, es la práctica probatoria; y la tercera, la fase de alegatos de conclusión. La primera fase, es el primer acercamiento que tienen las partes para exponer su pretensión, si es la Fiscalía, será la de pedir condena y, si es la defensa, será la absolución de los cargos. Es inexacto e incorrecto hablar de presentación de la teoría del caso, ya que esta es solo una metodología para abordar la investigación de los hechos y adecuarlos típicamente y delimitar el objeto de prueba. 
En la segunda, se recibirán los testimonios, se hará el interrogatorio, el contrainterrogatorio, el re directo si hay lugar a ello, según las reglas de los artículos 383, 391, 392,393, 395 del CPP. Se practicará la prueba pericial conforme los artículos 405 a 422 del CPP. Igualmente se incorporará la prueba documental conforme lo establecido en los artículos 424 a 434 del CPP.

En desarrollo del juicio oral, una vez escuchados los alegatos de conclusión, el Juez debe anunciar el sentido del fallo conforme lo establecen los artículos 445 y 446 del CPP, en caso de ser absolutorio el proceso termina y, si el acusado está privado de la libertad se ordenará su libertad inmediata tal y como lo establece el 449 del CPP. También, implica que la víctima no puede iniciar el respectivo incidente de reparación integral.

Si por el contrario el fallo es condenatorio, el Juez debe individualizar a quien será objeto de aplicación de una pena, deberá hacer alusión a lo pretendido en los alegatos finales y dará traslado por una sola vez de lo consagrado en el 447 del CPP, para que Fiscal y defensa se manifiesten sobre las condiciones de determinación y ejecución de la pena. Respecto de esta decisión procede el recurso de apelación.

\section{LOS RECURSOS}

Según el artículo 161 del CPP (Congreso de la República, 2004), las providencias judiciales pueden ser de tres tipos: sentencias, autos y órdenes. Estas providencias deben reunir los requisitos que se encuentran en el artículo 162 y que solo para el efecto se resaltarán los siguientes: "fundamentación fáctica, probatoria y jurídica con indicación de los motivos de estimación y desestimación de las pruebas válidamente admitidas en el juicio oral".

Ahora bien, cuando las decisiones adoptadas, sean estos autos o la propia sentencia no contengan los requisitos o se aparten del 162 del CPP (Congreso de la República, 2004), por regla general procederán los recursos de reposición y apelación. Haciendo la aclaración que contra la sentencia no procede el recurso de reposición.

Respecto del trámite del recurso de reposición este se interpone y sustenta en audiencia y el Juez lo resolverá de inmediato. Ahora bien, en lo que tiene que ver con el recurso de apelación, este se interpondrá en la audiencia y puede sustentarse allí o sustentar por escrito dentro de los cinco días siguientes a la audiencia, esto se modificó con la Ley 1395 de 2010 "descongestión de Despachos judiciales", la cual varió, entre otros, los artículos 90 y 91 e incorporó los artículos 179a y $179 \mathrm{~b}, 179 \mathrm{c}, 179 \mathrm{~d}, 179 \mathrm{e}, 179 \mathrm{f}$ que regularon la procedencia del recurso de Queja, trámite, concesión y efectos de este. También el asunto del desistimiento del recurso cuando este no se sustenta en el término establecido o se hace de manera deficiente.

En lo que tiene que ver con la sustentación de los recursos, si bien es cierto se pretende dar celeridad, no se puede olvidar los principios rectores como el de inmediación, el cual queda de lado mediante este mecanismo de sustentación inmediata en los casos de los autos o dentro de los 5 días siguientes en el caso de las sentencias, pareciera que esta ley fue redactada por personas ajenas al primigenio espíritu del sistema penal acusatorio. Esto hace pensar en un retorno al sistema mixto, amén de las varias complementaciones que por vía jurisprudencial viene haciendo la Honorable Corte Suprema de Justicia.

\section{LEY 1826 DE 2017}

Finalmente, la Ley 1826 de enero 12 de 2017, creó el nuevo procedimiento penal abreviado y reguló la figura del acusador privado. La finalidad de esta ley es la de descongestionar despachos judiciales de todas aquellas causas de poca trascendencia social. A través de esta legislación, el Congreso creó un procedimiento especial abreviado que, si bien respeta todas las garantías al debido proceso, hace mucho más corto el procedimiento penal para algunas conductas delictivas previamente establecidas.

En el Manual Nuevo Procedimiento Abreviado y Acusador Privado de la Fiscalía General de la Nación, se ratifica esta intención dando por probado que al acortar las etapas procesales se va a descongestionar la administración de justicia (2017, pág. 11). No obstante, han pasado tres años desde su aprobación y todo parece indicar que no ha servido a esos benévolos propósitos y, la congestión judicial ha seguido en aumento.

Ahora bien, con fundamento en lo anterior, y con el propósito de alcanzar los fines previamente expuestos, la Ley 1826 del 2017 también 
desarrolla la figura del acusador privado. Cabe aclarar que dicha institución tiene fundamento constitucional en el parágrafo 2 del artículo 250 de la Carta Política, el cual fue introducido por el Acto Legislativo 006 de 2011 en los siguientes términos:

Atendiendo la naturaleza del bien jurídico y la menor lesividad de la conducta punible, el legislador podrá asignarle el ejercicio de la acción penal a la víctima o a otras autoridades distintas a la Fiscalía General de la Nación. En todo caso, la Fiscalía General de la Nación podrá actuar de forma preferente (Asamblea Nacional Constituyente, 1991).

Así las cosas, se esperaría a que este nuevo procedimiento que, entre otras cosas, extendió su participación a los estudiantes adscritos al consultorio jurídico, y suprime la imputación pasando directamente a la etapa de acusación y audiencia concertada, contribuya a lo que en ausencia de una política criminal disminuiría el delito.

\section{REFORMAS A LA LEGISLACIÓN VIGENTE - ALGUNAS BREVES IDEAS PARA LA MEJORA DEL SISTEMA PENAL COLOMBIANO}

El sistema penal de corte adversarial pensado con la Ley 906 de 2004 está colapsado, las audiencias de libertad se están programando para dos o tres meses después. Los juicios se están programando de cuatro a cinco meses. Solo por dar unos datos que pueden ser fácilmente corroborados por quienes litigan en la ciudad de Bogotá y en otras principales ciudades, como Medellín.

Lo anterior evidencia que un sistema fue pensado y, otro el que materialmente se adoptó. Los Fiscales no hacen uso de los mecanismos de terminación anticipada del proceso penal que son la base o el éxito de estos sistemas. Precisamente, la Fiscalía no preacuerda y cuando lo hace corre el riesgo de que los jueces en virtud de un control material no aprueben el preacuerdo. Peor aún, es el escenario del principio de oportunidad donde artificiosamente el Fiscal debe, solicitar a un grupo de Fiscales de rango superior la aprobación de este, no es de extrañarse que dicho trámite demore meses, incluso años. Lo peor del asunto es que ese trámite interno no se encuentra en la ley, pero si se encuentra en una resolución (6657 y
6658 de 2004) interna de la Fiscalía que limita las facultades que la ley le otorga al Fiscal del Caso.

Por esto, es de celebrar la propuesta de Gómez, quien plantea un cambio de paradigma en cuanto al principio de oportunidad, siendo este la regla general y no la excepción (2020) Cabe recordar que la Constitución Política, al igual que los principios rectores parecerían indicar que la legalidad debería ser la regla general, no obstante, es el principio de oportunidad quien se compadece y estaría en consonancia con el programa penal de la Constitución Política de 1991.

Otro tanto ocurre con los allanamientos a cargos. La Fiscalía de manera desleal y oportunista imputa todo el Código Penal, sin respaldo probatorio, sin respaldo fáctico, cercenando una posibilidad de allanamiento por la injusticia de la imputación. Ocurre también que, como quiera que el catálogo de beneficios por colaboración va atado a las penas consagradas para cada delito y a una serie de artículos del Código Penal que limitan cualquier rebaja de pena, los indiciados se ven ante un escenario en el cual es mejor irse a juicio que aceptar los cargos porque la pena a imponer es igual.

Lo anterior, para decir que se requiere darle a la Fiscalía la facultad de terminar anticipadamente el proceso sin trámites burocráticos como ocurre con el principio de oportunidad. Igualmente, que los preacuerdos no estén limitados de manera arbitraria por los jueces y que se dé plena libertad a las partes para, dentro de los límites legales imponer una pena que se adapte a los intereses del Estado representados en la Fiscalía y a los intereses de la defensa material representados en la defensa técnica.

Otro asunto que está en mora de modificarse es el interviniente especial del Ministerio Público. Este interviniente sobra dentro del proceso penal. Desequilibra la balanza del sistema adversarial sin una justificación constitucional suficiente; al respecto, y desde la misma constitución, se dice que este interviniente está para proteger el orden y la legalidad. Si esto es así, cuál es acaso la función de los jueces, cuál es acaso la función de la Fiscalía, inclusive la de la propia defensa técnica que siempre debe velar porque se respeten las garantías de su representado. 
Los recursos que se han destinado para estos funcionarios podrían ser enfocados o redirigidos a la Defensoría Pública, inclusive la preparación y el alto nivel de algunos de los agentes del Ministerio Público harían que pudieran desempeñar esta labor de defensores de oficio de algunos procesos y de esta manera ayudar a la institución tan congestionada como la Defensoría Pública.

Se debe dejar claro que la salida del Ministerio Público del proceso penal requiere de una reforma constitucional en la cual se le supriman algunas de sus funciones y se elimine lo correspondiente a las partes en que es mencionado como un interviniente especial. En estricto sentido, se deberá eliminar el parágrafo primero del artículo 250 de la Constitución. Y el 277 en su numeral séptimo.

Por último, es grave que a los jueces los investiguen los Fiscales. Esto genera una relación de codependencia funcional e inclusive de falta de neutralidad al verse abocado el Juez a tomar una decisión que afecte gravemente los intereses de la Fiscalía. En otras palabras, se requiere que otra Entidad, diferente a la Fiscalía investigue y acuse a los Jueces.

Las anteriores consideraciones son algunas obvias y pueden estar sometidas a las más duras criticas. No obstante, la realidad procesal indica que son las mayores falencias del sistema.
Sin desconocer que hay profesionales, Jueces, Fiscales, Agentes del Ministerio Público que cumplen sus funciones a cabalidad y con el mayor rigor jurídico y ético.

\section{CONCLUSIONES}

El ordenamiento jurídico colombiano responde a principios constitucionales que han sido incluidos en los Códigos Penales con cláusulas específicas de aplicación directa a todas las decisiones y actuaciones que se tomen dentro del proceso.

El actual sistema procesal penal tiene una estructura bastante sencilla: audiencia de imputación en la cual se hace un acto de comunicación al procesado, radicación del escrito de acusación junto con la audiencia de acusación; posteriormente, la audiencia preparatoria en la cual se hará las solicitudes de practica de prueba que finalmente se practicarán en el juicio oral.

La tendencia actual es a simplificar el proceso antes descrito, por esto, en el proceso abreviado se elimina la audiencia de imputación y se encuentra concentrada en una sola audiencia, la acusación y la preparatoria.

Hay muchas cosas por mejorar dentro del sistema. Es apremiante la situación de colapso del sistema por la falta de coherencia de la política criminal.

\section{BIBLIOGRAFÍA}

- Arnaiz S., A., López J., R., \& Martínez S., T. (2013). Esquemas de Derecho Procesal Penal. (Moreno C., V., Edit.). Valencia: Tirant Lo Blanch.

- Asamblea Nacional Constituyente. (1991). Constitución Política. Gacetas Asamblea Constituyente Nos. 4, 5, 8, 12, 13, 21, 23, 24, $25,26 \mathrm{~A}, 28,34,35,39,62,83,84,87,90$, 112 y 119.

- Asamblea Nacional Constituyente. (1991). Constitución Política. Gacetas Asamblea Constituyente Nos. 4, 5, 8, 12, 13, 21, 23, 24, 25,26 A $28,34,35,39,62,83,84,87,90$, 112 y 119.
- Auto de sustanciación, AP1259-2019, radicado 54.930 (Corte Suprema de Justicia, 3 de abril de 2019).

- Auto de Sustanciación, AP 2356-2019. Radicado 50.213 (Corte Suprema de Justicia, 30 de Mayo de 2018).

- Auto Sustanciación, AP 5911-2015 Radicado:46.109 (Corte Suprema de Justicia, 8 de Octubre de 2015).

- Báez, J., Corbetta, P., Esquivel, C., Pablo, B., Bedoya, V. M., Finocchiaro, E. y Tizón, A. (2013). Derecho Procesal Penal. (C. Chiara Díaz, \& M. La Rosa, Edits.). Buenos Aires: Astrea. 
- Calaza L., S.; Cuadrado S., C.; Yolanda, D. D.; Fernández L., M.; Fuentes S., O., \& López Y., V. (2019). Derecho Procesal Penal. (Asencio M., J. M., edit.). Valencia: Tirant Lo Blanch.

- Congreso de la República. (12 de enero de 2017). Ley 1826. Diario Oficial No. 50.114.

- Congreso de la República. (1 de septiembre de 2004). Código de Procedimiento Penal Ley 906. Diario Oficial. No. 45.658.

- Congreso de Colombia. (24 de julio de 2000). Ley 600. Diario Oficial No. 44.097.

- Escuela Judicial Rodrigo Lara Bonilla. (2005). Reflexiones sobre el nuevo Sistema Procesal Penal. Bogotá: Escuela Judicial Rodrigo Lara Bonilla.

- Fiscalía General de la Nación. (2017). Manual Nuevo Proceso Abreviado y Acusador Privado. Bogotá.

- Montealegre, E., \& Bernal, J. (2013). Derecho Procesal Penal. Bogotá: Universidad Externado de Colombia.

- Pavajeau, G. (2020). Instituciones Procesales Penales. Tomo II. Bogotá: Universidad
Externado de Colombia.

- Presidencia de la República. (13 de enero de 1987). Decreto 050. Diario Oficial. Año CXXIII. No. 37754.

- Presidencia de la República. (1991). Decreto 2700. Diario Oficial. Año CXXIII. No. 37754. (13 de enero de 1987).

- Saray B., N. (2017). Procedimiento Penal Acusatorio. Bogotá: Leyer.

- Sentencia de Constitucionalidad, 559 (Corte Constitucional, 20 de Noviembre de 2019).

- Sentencia de Casación, 51.007 (Corte Suprema de Justicia, 5 de junio de 2019).

- Sentencia de Constitucionalidad, C - 396 (Corte Constitucional, 23 de Mayo de 2007).

- Sentencia Constitucionalidad, C - 228 (Corte Constitucional, M P: Manuel José Cepeda Espinosa, Manuel José; Lynett Montealegre, 3 de abril de 2002).

- Sentencia de Constitucionalidad, C - 516 (Corte Constitucional, M P Jaime Cordoba Tribiño, 11 de julio de 2007). 